\title{
On the Designing, Efficiency, and Stirring Force of an Induction Coil for the Processing of Prototype Al Based Nanocomposites
}

\author{
Muhammad Mansoor and Muhammad Shahid \\ School of Materials and Chemical Engineering, National University of Sciences and Technology, Islamabad 46000, Pakistan \\ Correspondence should be addressed to Muhammad Mansoor; muhammadmansoor@scme.nust.edu.pk
}

Received 29 September 2014; Accepted 16 December 2014; Published 31 December 2014

Academic Editor: Brij Kumar Dhindaw

Copyright ( 2014 M. Mansoor and M. Shahid. This is an open access article distributed under the Creative Commons Attribution License, which permits unrestricted use, distribution, and reproduction in any medium, provided the original work is properly cited.

Induction melting could be a potential fabrication method for aluminum matrix nanocomposites, owing to its characteristics stirring action and rapid heating. In the present work, an induction coil for small scale composite fabrication was designed through geometric, thermal, and electromagnetic analyses. Subsequently, the designed coil was simulated for its thermal efficiency and stirring force using finite element method magnetics software. The designed coil yielded more than $60 \%$ of the total energy supplied into thermal efficiency with a stirring force $<3 \mathrm{mN}$, which could be significant for efficient melting and stirring to fabricate the aluminum matrix nanocomposites.

\section{Introduction}

All over the word, aluminum based nanocomposites are gaining interest of the researchers exponentially, owing to the facts of their higher mass to strength ratio, ease of fabrication, lower processing temperatures, wide compositional range, and lower costs. However, due to the density differences and nonwetting behavior of molten aluminum, dispersion of strengthening phases or nanoparticles in aluminum matrix is one of the prime issues. Since last decade, many researchers tried to improve the second phase dispersion by powder precursor casting [1], stir casting [2], compo-casting [3], ultrasonic assisted casting [4], and squeeze casting [5]. Although the efforts were successful with respect to the dispersion of strengthening phases certain limitations were always associated with them, for example, contamination from the stirrer in case of stir and compo-castings, limited melt size in case of ultrasonic assisted casting, and reduced melt penetration in larger section for squeeze casting. Moreover, all of the techniques require the specialized type of equipment and capabilities to handle and process molten aluminum, consequently, increasing capital and processing costs.

Alternatively, induction melting could be a solution to the problem featuring compositional consistency, liberty of melt quantity, ease of processing, lower costs, and innate stirring. The consequential stirring action of induction melting eliminates any need of external stirrer. In the present work, design parameters of an induction coil were calculated for prototype fabrication of aluminum based nanocomposites. Furthermore, heating efficiency and stirring force induced by the designed coil were evaluated using "finite element method magnetic" version 4.2 (FEMM).

\section{Background}

An induction melting unit comprises a workpiece, an induction coil, load-matching station, and power supply. Besides other parameters, optimum heating could be achieved by designing a compatible and a specific heating coil for a particular application. The heating process involves many factors like electromagnetism, heat transfer, and metallurgical phenomena. Physical properties of the workpiece (usually a metallic material) change with temperature; hence variation in induced electromagnetic and heat transfer will occur [6].

The basic mechanism of induction heating is quite simple, where alternating current is produced in a coil (i.e., induction coil) by applying alternating voltage. The alternating current produces magnetic field (of the same frequency) in the vicinity of the coil. The strength of the magnetic field 
produced depends upon various parameters of the coil like current, geometry, and distance. A workpiece, placed in the coil, experiences eddy currents due to the varying magnetic fields around it. The coil currents and induced eddy currents have the same frequencies but opposite in direction. The induced eddy currents generate separate magnetic fields in opposite direction to the magnetic fields of the coil. Therefore, the induction coil produces a net magnetic field of source and induced magnetism. The induced eddy currents in the workpiece generate heat in a thin surface layer, called skin depth, by ohmic or Joule effect $[6,7]$. Besides heating, the induced eddy currents $(j)$ generate Lorentz force $(F)$ in the presence of magnetic flux $(B)$ according to

$$
F=j \times B
$$

In molten form, the conductor behaves as an incompressible fluid and due to the Lorentz force it moves, resulting in continuous stirring of the melt $[8,9]$. A schematic of the stirring action of an induction furnace is shown in Figure 1.

Electrical resistivity $(\rho)$ and relative magnetic permeability $\left(\mu_{r}\right)$ are very important properties of the materials affecting all major parameters of an induction system, for example, skin depth, stirring, heat distribution, coil impedance, and coil efficiency. Induction heating is handy, rapid, localized, and economical heating method, frequently used in industry [10].

\section{Coil Design Analyses}

"No Toil, No Coil" is a common saying of the induction coil designers. Whatever the type of induction heating (with core or coreless) is under consideration, coil is a crucial part, always demanding utmost efforts and time. A major reason for the criticality of coil design is the need of a particular type of coil for a particular application to have optimum results. In the present work, it is required to melt aluminum in a small crucible with maximum stirring action. Therefore, specific design parameters (i.e., geometrical, thermal, and electromagnetic) are analyzed to optimize the coil design.

The design is based upon the conditions given in Table 1. These conditions are set according to the experimental requirements and limitations posed by available induction generator.

3.1. Geometrical Analysis. As described in Table 1, aluminum $(100 \mathrm{~g})$ is required to melt in a cylindrical alumina crucible. The dimensions of the crucible [11] and volume of the melt are calculated using (2) and (3), respectively, as follows:

$$
\begin{gathered}
\frac{H}{D}=(1.6-2.0) \\
V=\frac{\pi d^{2} H}{4},
\end{gathered}
$$

where $H$ and $D$ are height and diameter of molten metal in the crucible, respectively.

The internal diameter $\left(D_{\mathrm{o}}\right)$ of the induction coil is a function of crucible diameter $\left(D_{c}\right)$, crucible wall thickness

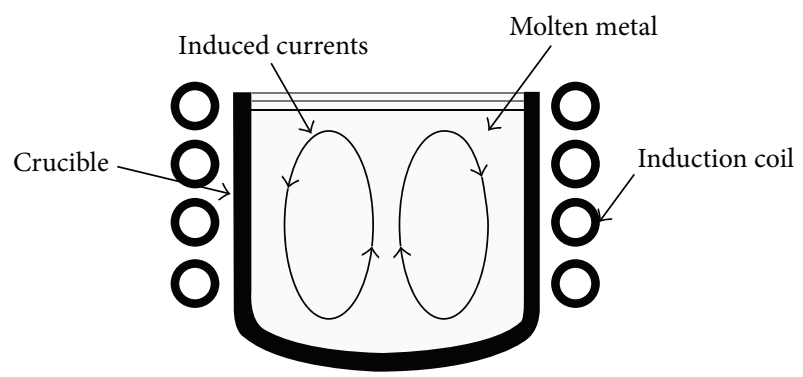

Figure 1: Schematic diagram of an induction furnace showing stirring action in the molten pool.

Table 1: Preconditions used for the designing of the induction coil.

\begin{tabular}{lc}
\hline Material to melt & Aluminum \\
Capacity of the furnace & $0.1 \mathrm{Kg}$ \\
Crucible material & Sintered alumina \\
Crucible shape & Cylindrical \\
Wall thickness of the crucible & $2 \mathrm{~mm}$ \\
Gap between coil and the crucible & $5 \mathrm{~mm}$ \\
Material of coil pipe & $\mathrm{ETP}^{*} \mathrm{copper}$ \\
External diameter of copper pipe & $5 \mathrm{~mm}$ \\
Internal diameter of copper pipe & $4 \mathrm{~mm}$ \\
Frequency of power supply & $10 \mathrm{KHz}$ \\
Current of power supply & $100 \mathrm{~A}$ \\
\hline
\end{tabular}

${ }^{*}$ Electrolytic tough pitch copper.

$\left(B_{w}\right)$, and insulation thickness $\left(B_{\text {ins }}\right)$ and is determined using $[11,12]$

$$
D_{\circ}=D_{c}+\left(B_{w}+B_{\text {ins }}\right) .
$$

Height of the inductor coil $\left(H_{\circ}\right)$ depends upon the height of the workpiece or the melt $(H)$, which is usually kept 1.1 to 1.2 times of the $H$ [12]:

$$
H_{\circ}=(1.1 \sim 1.2) H .
$$

3.2. Thermal Analysis. The heat energy required $\left(Q_{r}\right)$ to process the aluminum includes energy to melt aluminum $\left(Q_{a}\right)$, energy to superheat $\left(Q_{s}\right)$, energy to melt slag $\left(Q_{g}\right)$, energy for endothermic reaction $\left(Q_{e}\right)$, and energy liberated by any exothermic reaction $\left(Q_{x}\right)[13]$ :

$$
\begin{gathered}
Q_{r}=Q_{a}+Q_{s}+Q_{g}+Q_{e}+Q_{x}, \\
Q_{a}=m C\left(T_{\circ}-T\right)+E,
\end{gathered}
$$

where $m$ is mass of charge in $\mathrm{Kg}, C$ is specific heat capacity of aluminum and is equal to $1100 \mathrm{~J} / \mathrm{Kg} \cdot \mathrm{K}, T_{\text {。 }}$ is melting temperature ( $933 \mathrm{~K}$ for aluminum), and $T$ is room temperature $(298 \mathrm{~K}) . E$ is the heat energy required for any phase transformations, which would be zero for pure aluminum.

Similarly,

$$
Q_{s}=m C_{\circ} T_{s},
$$

where $C_{\circ}$ is heat capacity of aluminum in molten form $(992 \mathrm{~J} / \mathrm{kg} \cdot \mathrm{K})$ and $T_{s}$ is the superheating temperature $(323 \mathrm{~K})$. 


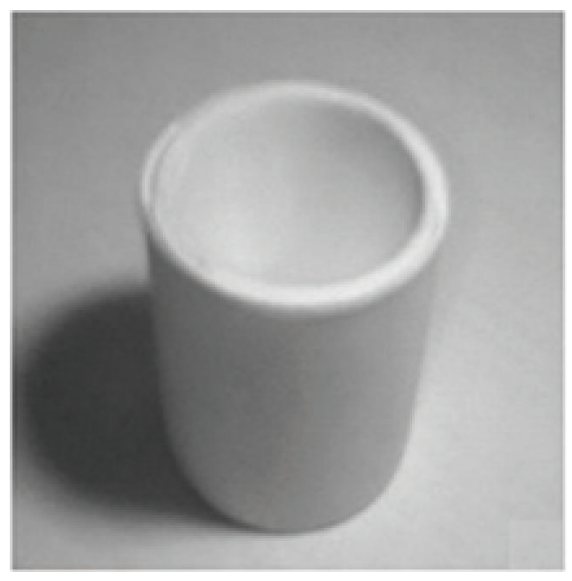

(a)

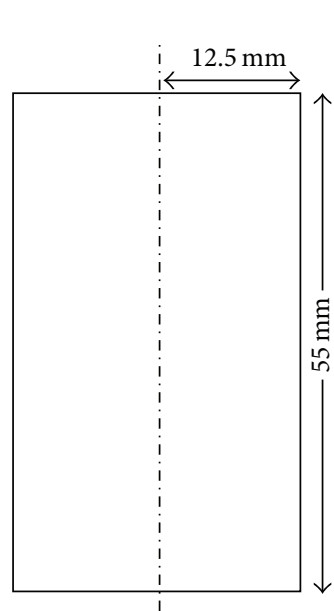

(b)

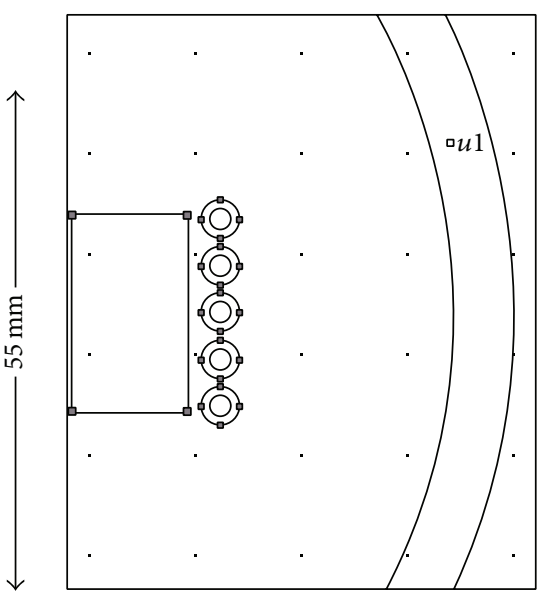

(c)

FIGURE 2: (a) Actual crucible used for melting, (b) transversal cutting of the crucible used for simulation, and (c) FEMM drawing.

Also,

$$
Q_{g}=m_{g} C_{g}
$$

where $m_{g}$ is the amount of slag, which is considered $8 \%$ of the total melt, and $C_{g}$ is slag heat energy $(18 \mathrm{KJ} / \mathrm{kg})$.

3.3. Electromagnetic Analysis. The heat energy produced $\left(Q_{p}\right)$ to melt the charge in the form of eddy currents is a function of frequency of the power supply $(f)$, height of the workpiece $(H)$, maximum magnetic flux density $(B)$, diameter of the workpiece $(D)$, and resistivity $(\rho)$ of the work piece (which is $2.83 \times 10^{-8} \Omega \mathrm{m}$ for aluminum). The function is shown in $[11,14]$

$$
Q_{p}=\frac{\pi^{3} f^{2} H B^{2} D^{4}}{8 \rho}
$$

or

$$
B=\sqrt{\frac{8 \rho Q_{p}}{\pi^{3} f^{2} D^{4} H}}
$$

and also

$$
Q_{p}=\frac{Q_{r}}{t}
$$

where $t$ is time in seconds to attain maximum flux.

The current density in the inductor is

$$
I_{a}=\frac{I}{A}
$$

To produce required amount of magnetic flux density $(B)$, number of turns of the inductor coil could be estimated by [11-15]

$$
B=\frac{\mu \mu_{\mathrm{o}} N I}{L}
$$

or

$$
N=\frac{B L}{\mu_{0} I},
$$

where $\mu$ and $\mu_{0}$ are relative permeability and permeability of workpiece material and free space, respectively. Relative permeability of nonmagnetic materials is equal to 1 , and permeability of free space is $4 \pi \times 10^{-7} \mathrm{Tm}^{-1}$. $L$ is length of the inductor, which is $H$ in present work. The current passing through the inductor is $I$, in amperes.

3.4. Efficiency of the Designed Induction Heating System. After defining the design parameters it is necessary to evaluate the efficiency of the designed coil prior to its practical implementation. Walter and Ceglia [16] proposed a mathematical model (16) for the evaluation of heating efficiency of induction coil:

$$
\eta_{\circ}=\frac{R_{s}}{R_{s}+R_{p}} \times 100,
$$

where $\eta_{0}$ is percentage heat efficiency of the coil, $R_{p}$ is the primary coil resistance, and $R_{s}$ is load (or secondary coil) resistance. The losses within the induction coil are associated with the resistance of the coil $\left(R_{p}\right)$ and, therefore, kept to minimum values. However, $R_{s}$ defines the extent of induced energy in the workpiece and should be maximized.

3.5. Simulation. To find the values of $R_{p}$ and $R_{s}$, simulation based upon calculated parameter of the induction coil was carried out using FEMM. Geometry of the heating system was defined in FEMM according to Figure 2, where external diameter of the workpiece (aluminum) was taken as the diameter of the crucible neglecting the actual material of the crucible (alumina), which was inactive for magnetic inductions, whereas copper was taken as coil material.

The simulation was required for axisymmetric condition; therefore only a traversal cutting of the crucible was drawn (Figure 2(c)). According to the program's algorithm, FEMM 


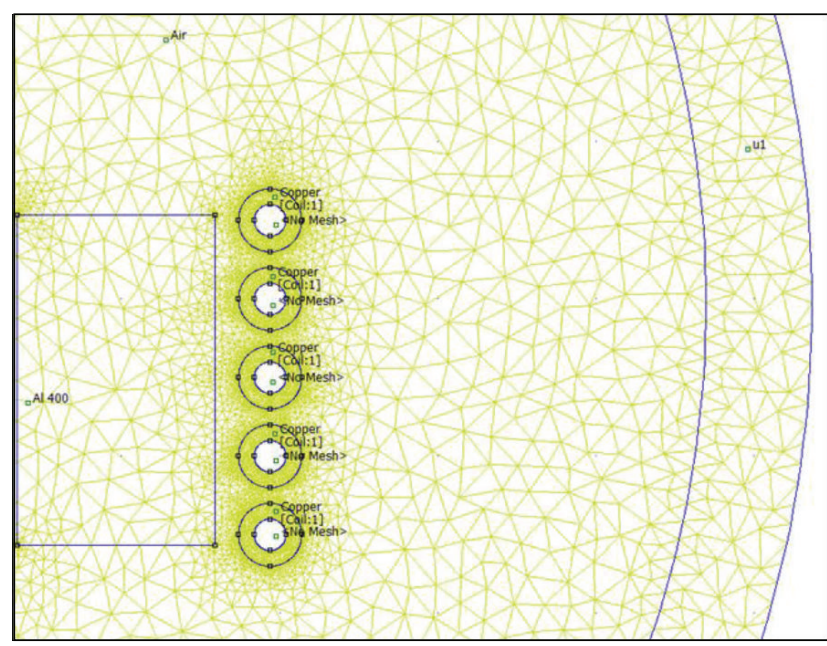

(a)

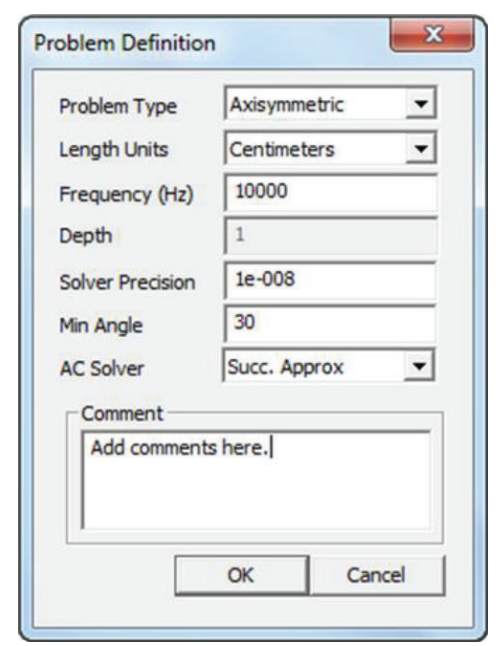

(b)

FIGURE 3: (a) Definition of all the working areas and respective materials and (b) preprocessor parameters used to define the problem.

first determined the magnetic contributions of $2 \mathrm{D}$ slice and then evaluated remaining by full revolution imparting the solid.

All the regions were defined in the preprocessor of the FEMM with their respective materials to realize the working problem; that is, workpiece was defined as "Aluminum 1100 " and conductors of the coil were defined as "Copper" having electrical conductivity values of 34.45 and $58 \mathrm{MS} / \mathrm{m}$, respectively. The copper coil was defined in one circuit named "coil" and environment around the workpiece and inductor was defined as "air." The inside area of the copper tube was not used in the simulation hence defined as "No mesh" (Figure 3).

\section{Results and Discussion}

The calculated geometrical parameters of the required coil for the melting of $100 \mathrm{~g}$ aluminum are given in Table 2. A total clearance of $7 \mathrm{~mm}$ was kept to accommodate alumina crucible having $2 \mathrm{~mm}$ wall thickness and working clearance of $5 \mathrm{~mm}$. No additional insulation layer was used between the crucible and the coil. Height of the coil was determined using (5) with upper allowable limit to induce maximum magnetic flux in the workpiece; however, not more than $20 \%$ of the height of the molten surface remained.

Total thermal energy required by the system is $\sim 105 \mathrm{KJ}$, as calculated by (6). The system under consideration entails melting of pure metal and incorporation of strengthening particles, which will remain unmelted and/or inert within the melt; therefore, for the calculation, endothermic $\left(Q_{e}\right)$ and exothermic $\left(Q_{x}\right)$ energy changes were considered equal (i.e., $Q_{e}=Q_{x}$ theoretically).

A very critical aspect of an induction coil is "number of turns," which was determined after calculating induced magnetic flux and current densities. The calculated turns were rounded-off to five and a pitch of $8 \mathrm{~mm}$ was maintained during fabrication the coil. Results of the theoretical analyses are given in Table 2 .
TABLE 2: Results of the design analyses.

\begin{tabular}{lc}
\hline Geometrical analysis & \\
Height of molten metal $(H)$ & $5.5 \mathrm{~cm}$ \\
Diameter of molten metal $(D)$ & $3.0 \mathrm{~cm}$ \\
Volume of the molten melt $(V)$ & $38.9 \mathrm{~cm}^{3}$ \\
Internal diameter of the induction coil $\left(D_{\circ}\right)$ & $4.5 \mathrm{~cm}$ \\
Height of the inductor coil $\left(H_{\circ}\right)$ & $6.0 \mathrm{~cm}$ \\
Thermal analysis & \\
Energy to melt aluminum $\left(Q_{a}\right)$ & $69850 \mathrm{~J}$ \\
Energy to superheat molten aluminum $\left(Q_{s}\right)$ & $32042 \mathrm{~J}$ \\
Energy to melt slag $\left(Q_{g}\right)$ & $144 \mathrm{~J}$ \\
Total heat energy required $\left(Q_{r}\right)$ & $102036 \mathrm{~J}$ \\
Electromagnetic analysis & \\
$\quad$ Maximum magnetic flux density $(B)$ & $0.00409 \mathrm{~T}$ \\
Current density through the coil $\left(I_{a}\right)$ & $5.67 \mathrm{~A} \cdot \mathrm{mm}^{-2}$ \\
Number of turns of the coil $(N)$ & $4.47 \mathrm{turns}$ \\
\hline
\end{tabular}

As operational and geometrical parameters were defined (Tables 1 and 2), the simulation of the heating system was generated using FEMM for the distribution of magnetic field intensities. Magnetic flux distribution in the workpiece and around the inductor is shown in Figure 4(a). The electrical parameters of the heating circuit were evaluated using a postprocessor facility provided by FEMM. The results are shown in Figure 4(b). The parameter "Voltage/Current" directly yields the value of $\left(R_{p}+R_{s}\right)$ of (16). To obtain $R_{p}$ value, an additional simulation was carried out where no load or workpiece was used (Figures 4(c) and 4(d)), which was done by eliminating workpiece while keeping all other parameters [16]. Therefore,

$$
\begin{gathered}
R_{p}+R_{s}=0.01274 \Omega \text { or } \cong 12.7 \mathrm{~m} \Omega, \\
R_{p}=0.004768 \Omega \text { or } \cong 4.77 \mathrm{~m} \Omega .
\end{gathered}
$$




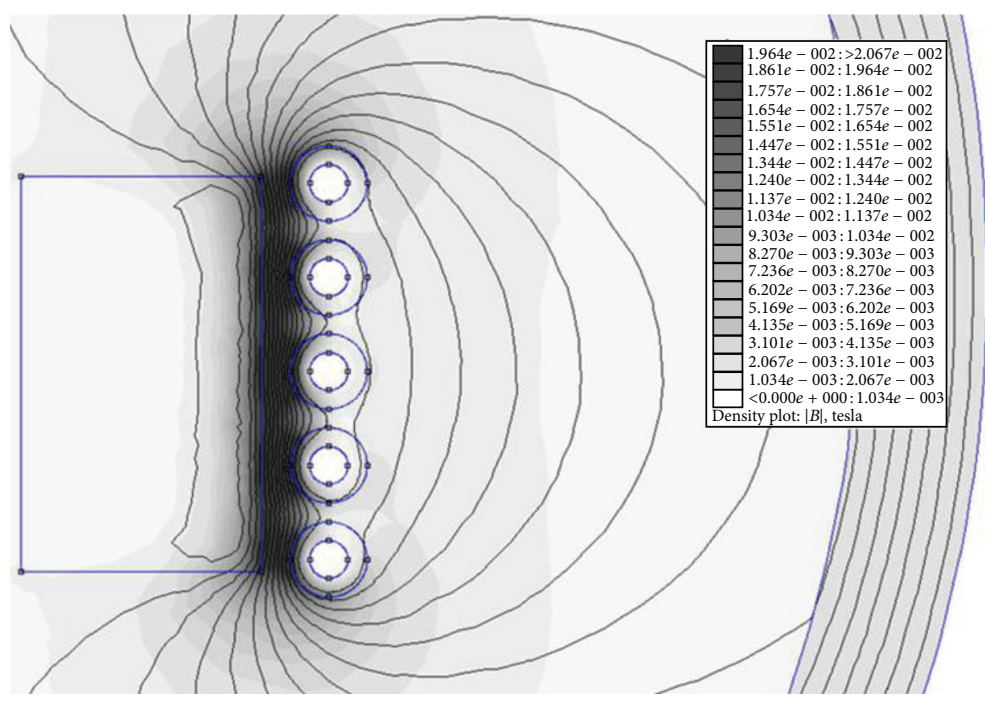

(a)

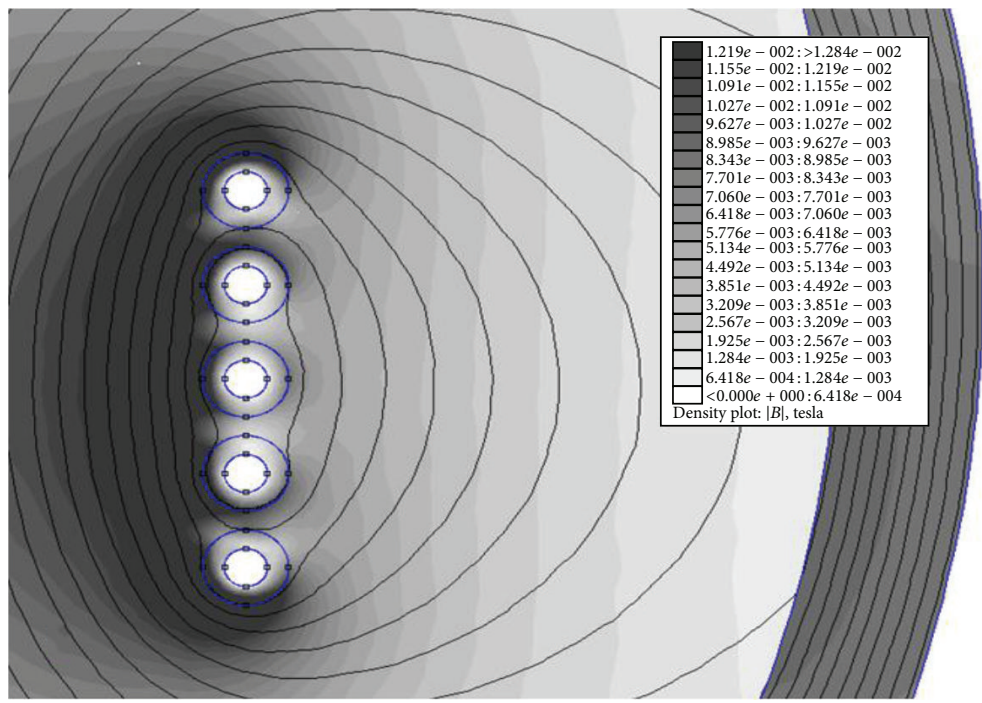

(c)

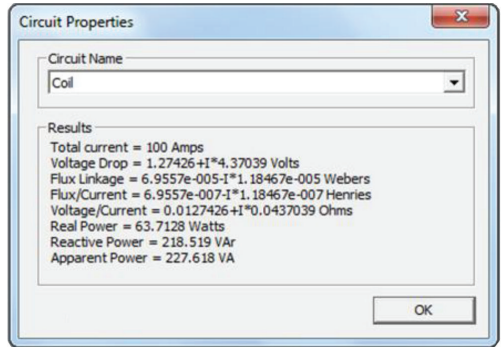

(b)

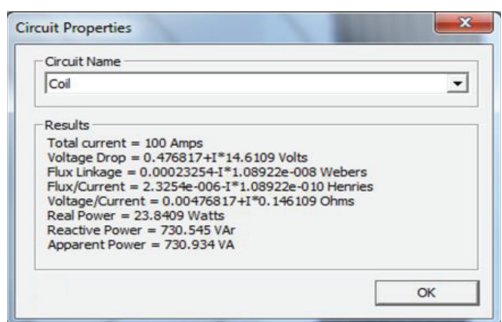

(d)

Figure 4: (a) Magnetic flux distribution in the designed coil system. (b) postprocessor results of the circuit "coil." (c) and (d) same as "(a) and (b)" but workpiece is eliminated.

Thus, according to (16),

$$
\eta_{\circ}=\frac{R_{s}}{R_{p}+R_{s}} \times 100=62.6 \% .
$$

Similarly, Lorentz force exerted by the induced magnetic flux in the workpiece was determined using postprocessor option of FEMM. Lorentz force is the cross product of magnetic flux density and induced current, that is, (1). To determine the Lorentz force induced in the workpiece, contour points of the workpiece were selected to define the area. Subsequently, block integral (a provision of FEMM postprocessor) was carried out by selecting "Lorentz force" option, which calculated a force of $2.45 \mathrm{mN}$ generated in the workpiece under the given preprocessor conditions. When the workpiece (aluminum) will become molten, the generated force may stir the melt smoothly and avoid settling of the reinforcing nanoparticles.
As pure aluminum is excellent conductor of electricity and heat, small amount of eddy currents will be generated during induction heating. However, the generated heat will transfer rapidly to the areas away from the proximity of the induction coil. Therefore, it would be beneficial to use relatively larger pieces of aluminum than smaller ones. Additionally, large pieces having lower surface areas will be less exposed to oxidation, resulting in ease of melting along with low entrapped oxides.

\section{Conclusions}

An induction coil was designed and analyzed for its geometrical, thermal, and electromagnetic parameters. The heating efficiency as well as induced stirring force of the coil was determined using FEMM. At the induction generator 
parameters (i.e., frequency of $10 \mathrm{KHz}$ and current of $100 \mathrm{~A}$ ) a heating efficiency $>60 \%$ and stirring force $<3 \mathrm{mN}$ were achievable.

\section{Conflict of Interests}

The authors declare that there is no conflict of interests regarding the publication of this paper.

\section{References}

[1] K. P. So, I. H. Lee, D. L. Duong et al., "Improving the wettability of aluminum on carbon nanotubes," Acta Materialia, vol. 59, no. 9, pp. 3313-3320, 2011.

[2] X. Zeng, G. Zhou, Q. Xu, Y. Xiong, C. Luo, and J. Wu, "A new technique for dispersion of carbon nanotube in a metal melt," Materials Science and Engineering A, vol. 527, no. 20, pp. 53355340, 2010.

[3] B. Abbasipour, B. Niroumand, and S. M. Monir Vaghefi, "Compocasting of A356-CNT composite," Transactions of Nonferrous Metals Society of China, vol. 20, no. 9, pp. 1561-1566, 2010.

[4] S. Donthamsetty, N. R. Damera, and P. K. Jain, "Ultrasonic cavitation assisted fabrication and characterization of A356 metal matrix nanocomposite reiforced with Sic, B4C, CNTs," Asian International Journal of Science and Technology in Production and Manufacturing Engineering, vol. 2, no. 2, pp. 27-34, 2009.

[5] A. B. Elshalakany, T. A. Osman, A. Khattab, B. Azzam, and M. Zaki, "Microstructure and mechanical properties of MWCNTs reinforced A356 aluminum alloys cast nanocomposites fabricated by using a combination of rheocasting and squeeze casting techniques," Journal of Nanomaterials, vol. 2014, Article ID 386370, 14 pages, 2014.

[6] V. I. Rudnev, D. Loveless, R. Cook, and M. Black, Handbook of Induction Heating, Marcel Dekker, New York, NY, USA, 2003.

[7] Y. Zhang and Y. Zhai, "Magnetic induction heating of nanosized ferrite particle," in Advances in Induction and Microwave Heating of Mineral and Organic Materials, S. Grundas, Ed., InTech, 2011, http://www.intechopen.com/books/advances-ininduction-andmicrowave-heating-of-mineral-and-organic-materials/magnetic-induction-heating-of-nano-sized-ferrite-particle.

[8] H. K. Moffatt, "Electromagnetic stirring," Physics of Fluids A, vol. 3, no. 5, pp. 1336-1343, 1991.

[9] http://autonopedia.org/crafts-and-technology/metalwork/metalworking-the-basics/metalworking-2-metals/.

[10] Practical Induction Heat Treating, ASM Handbook, ASM International, Materials Park, Ohio, USA, 2001.

[11] M. W. Kennedy, Fields and induced power in the induction heating of aluminium billets [Licentiate Thesis], School of Industrial Engineering and Management Department of Materials Science and Engineering Royal Institute of Technology, Stockholm, Sweden, 2013.

[12] V. G. Voskoboinikov, V. A. Kudrin, and A. M. Yakuchev, Obshaya Metallurgiya, Moscow, Russia, 1985.

[13] K. C. Bala, "Design analysis of an electric induction furnace for melting aluminum scrap," AU Journal of Technology, vol. 9, no. 2, pp. 83-88, 2005.

[14] J. T. Vaughan and J. W. Williamson, "Design of inductionheating coils for cylindrical nonmagnetic loads," Transactions of the American Institute of Electrical Engineers, vol. 64, no. 8, pp. 587-592, 1945.
[15] P. Hammod, Electromagnetism for Engineers-An Introductory Course, Pergamon, London, UK, 1978.

[16] J. Walter and G. Ceglia, "Using numerical methods to design and control heating induction systems," in Advances in Induction and Microwave Heating of Mineral and Organic Materials, S. Grundas, Ed., InTech, 2011. 

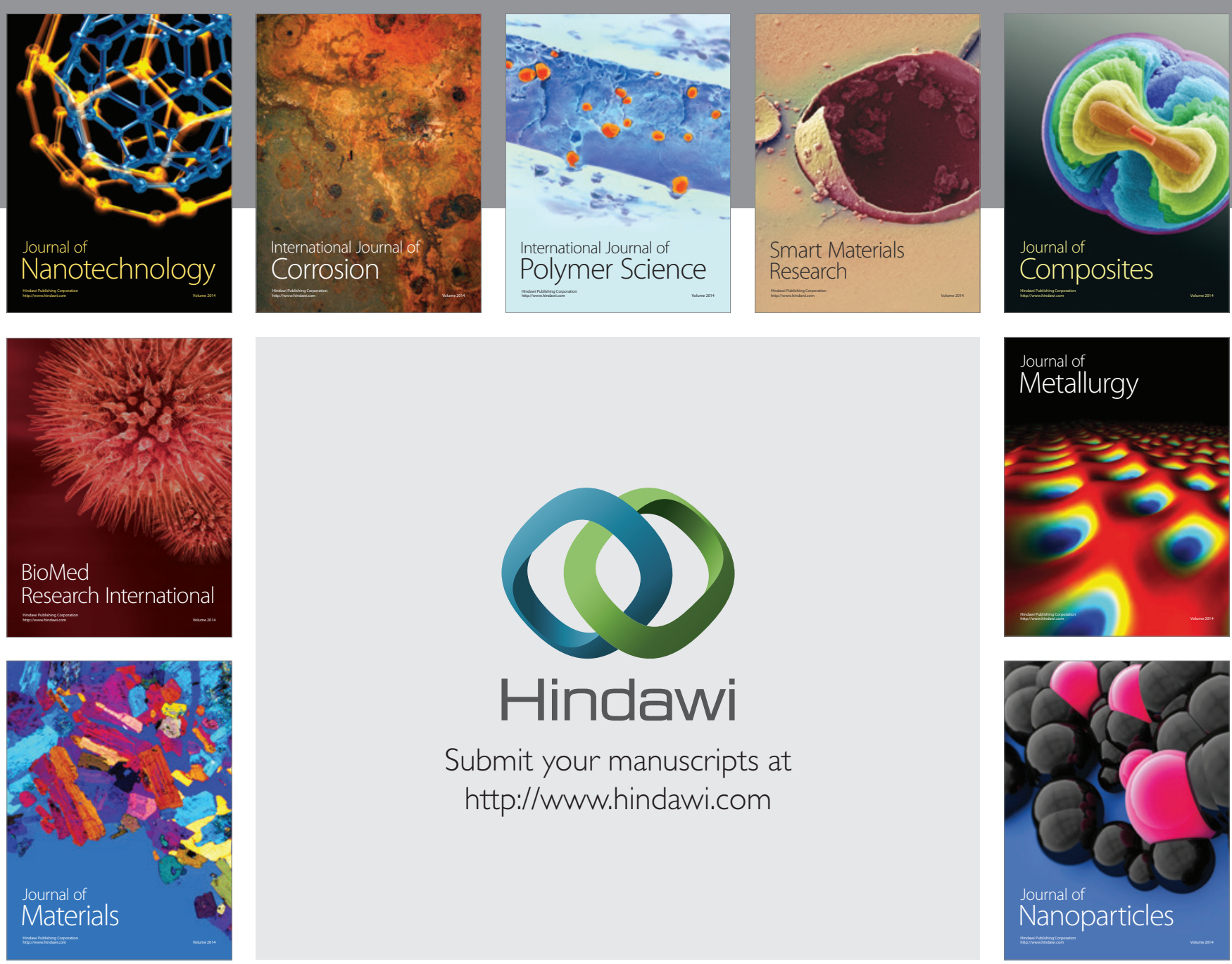

Submit your manuscripts at http://www.hindawi.com
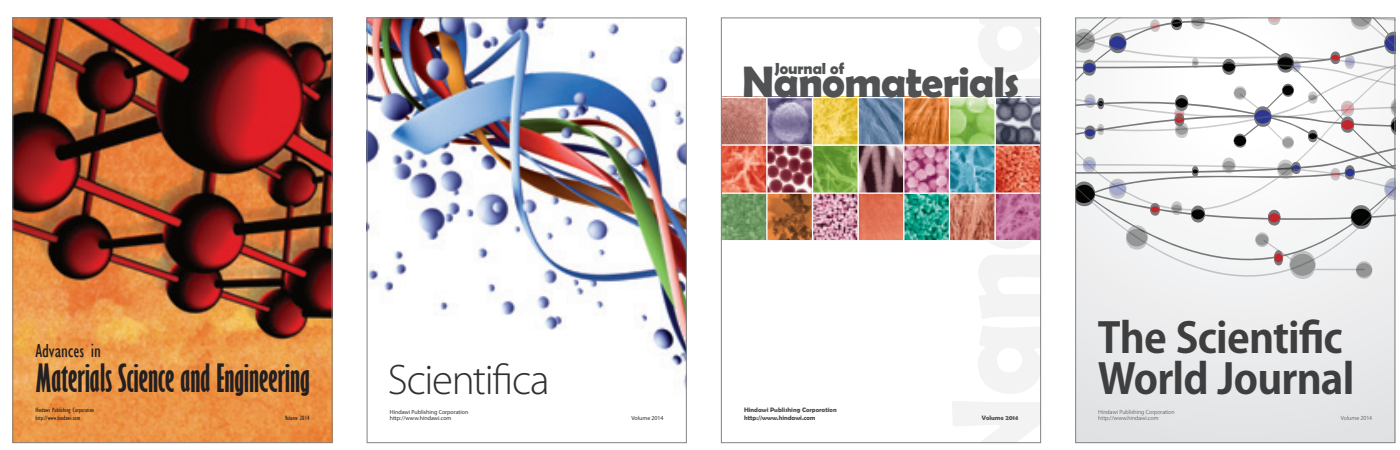

\section{The Scientific World Journal}
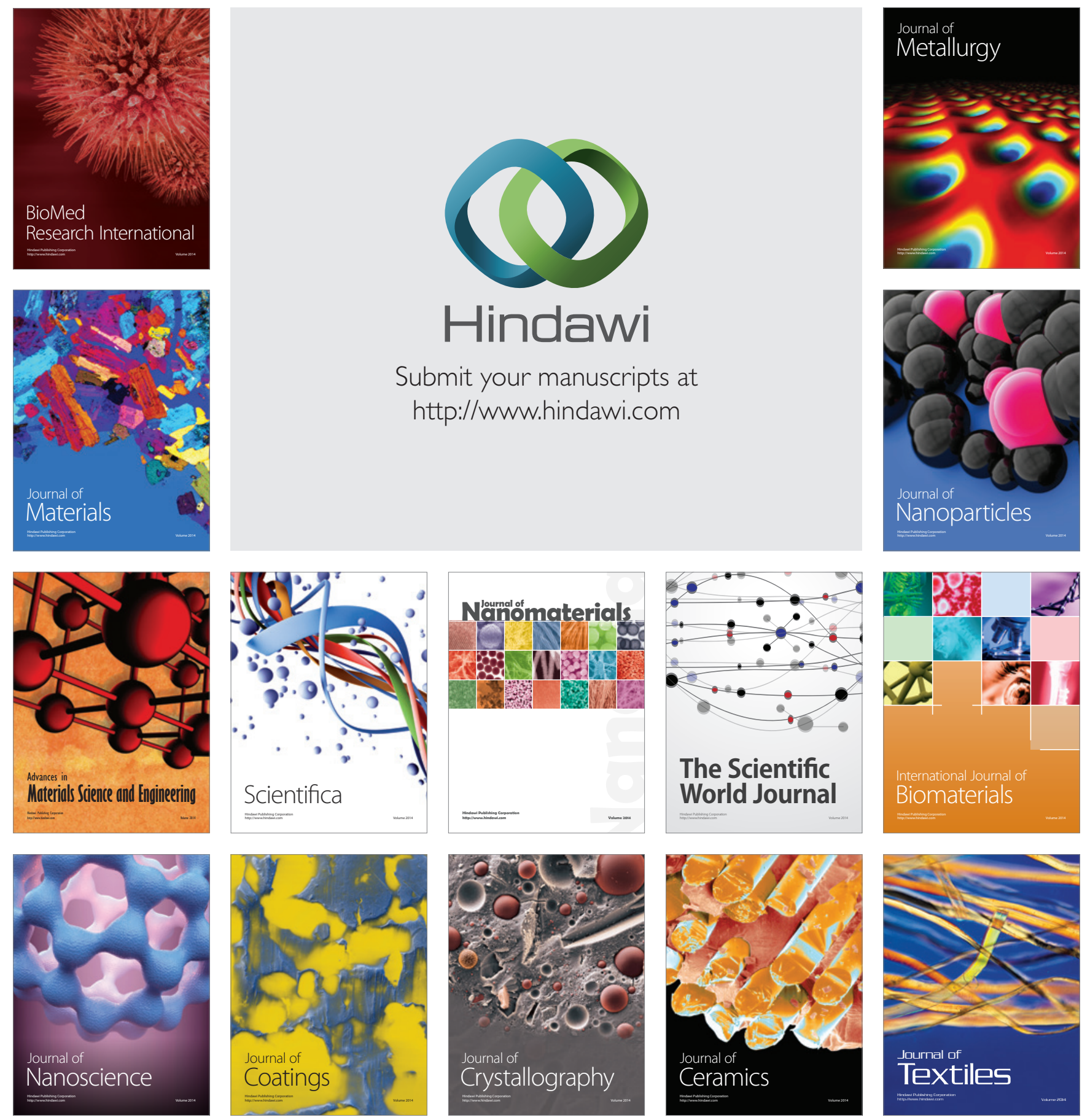